Adjoining the ballet room was another for ladies, 18 feet by 16 feet by 6 feet. It contained, as did the other, no means for changing the air except the doorway, and a defective wooden partition which separated it from a disused watercloset. In both rooms, as also in the "supers" room, were lavatory basins with $1 \frac{1}{2}$-inch iron waste pipes choked with soap, etc. These conditions are now in course of improvement; the floors of the basement rooms are to be lowered, proper ventilation provided, and the whole drainage system is to be thoroughly overhauled and reconstructed, all earth saturated with sewage being removed, and efficient light and ventilation provided for cloak and other rooms. Water is to be laid on, with proper waste-preventing cisterns to all waterclosets and to urinals to discharge automatically.

\section{The Almambra.}

The present building was erected in 1883 , the old Alhambra having been burned in the preceding year. The body of the house is well ventilated through the sun-light at the top of the dome, through the minarets in front, and through an open grating 4 feet high, which runs round the whole of the base of the dome, and communicates with the outer air through numerous windows. The same, however, cannot be said of the ladies' dressing rooms and of the various cloak and lavatory rooms.

The dressing rooms on the "prompt" side are three in number, one above the other, and each accommodates about twenty ladies of the ballet and has thirteen gas jets, with a cubic space of about 5,000 feet. The initial air space calculated on the requirements of the Factory and Workshops Acts would give the proper allowance of air to sixteen persons and twelve gas jets, but this low standard presupposes sufficiency of ventilation, which does not exist here. At one end of each room is a window (one room has two) with openings 2 feet by 2 feet 3 inches, some feet from the ceiling; this forms an inlet and the door an outlet to the staircase for the air. These rooms abut upon an external wall, and an efficient means of outlet for the polluted air might be secured by providing a cone over each gas jet, communicating with a pipe passing through the wall and upwards outside for 10 or 12 inches, and ending in a cone-shaped cap to prevent entrance of rain. Two waterclosets are placed upon landings on the staircase just outside dressing room doors, and are only enclosed by a low partition open at the top to the air of the staircase. Running from top to bottom of the building is a shaft open at the top. and into this on the dressing room side openings provided with mica flap valves have been made on each landing. On the other side of the shaft the cloak rooms and lavatory arrangements for the audience have been placed, and they also similarly have openings into it. These openings, however, are not sufficient, especially so in the gallery urinals, where is a disused watercloset, which should be cut off from the soil pipe. The ventilation of all these places throughout the house is susceptible of improvement.

The larger part of the basement is used as a wine and beer cellar; it is paved with concrete and carefully ventilated, the same temperature being maintained as closely as possible throughout the year. Under the orchestra is the band room, which is not much occupied; it is lighted by gas, has no windows, and is ventilated through holes in the wall into a passage. The well under the stage is concreted, and at the back is a mineral water manufactory, the water being obtained direct from the main.

In the basement under the stage entrance in Hunt Court is the workmen's lavatory, containing a five-stall urinal and two waterclosets. The only means of ventilation is through an area into the courtway, and, judging by the smell, this did not seem sufficient. While the drains on the other side of the theatre have no means of access to them, on this side, in the workmen's lavatory, is an inspection chamber, with an interceptor trap and fresh air inlet in Hunt Court. Several of the principal artists' dressing rooms are on this-the north or O.P.-side of the building, and are ventilated directly into the open air of Hunt Court.

With few exceptions the water for the waterclosets is drawn direct from large cisterns situated at the top of the gallery on either side, and in many instances the flush of water is insufficient for the purpose. It would be well to provide water waste-preventing cisterns to each closet.
Both electricity and gas are used, but gas only is laid on to the dressing rooms. The formation of Charing Cross Road has removed a number of small buildings which hemmed in the Alhambra, and it now stands almost entirely clear of the surrounding buildings.

\section{BRITISH MEDICAL ASSOCIATION.}

\section{Thr ANNUal MUSEUM.}

THF Museum in connection with the sixty-first annual meeting of the British Medical Association will be arranged in the following Sections:-

Srction A.-Foods and Drugs, including Prepared Foods, Chemical and Pharmaceutical Preparations, etc. (Honorary Secretary, Dr. George R. Murray, 2, Saville Place, Newcastleon-Tyne.)

SkCrron B.-Pathology, comprising Models, Casts, NakedEye and Microscopic Preparations, Diagrams, etc. (Honorary Secretary, Dr. A. S. Percival, 16, Ellison Place, Newcastle-onTyne.)

Srctron C.-Anatomy and Physiology, including Dissections, Methods of Preparations, Models, Drawings, NakedEye and Microscopical Specimens, Microtomes, New Physiological Apparatus, etc. (Honorary Secretary, Dr. John Clay, Durham University College of Medicine, Newcastle-on-Tyne.) SFCTION D.-Surgical Instruments and Appliances, Books, and Microscopes, including New Books, Diagrams, Medical and Surgical Instruments and Appliances, Microscopes, etc. (Honorary Secretary, Mr. W. G. Richardson, F.R.C.S., The Dispensary, Newcastle-on-Tyne.)

Stction E.-Sanitary and Ambulance Appliances, comprising Appliances connected with the various branches of Sanitation, Ambulance Apparatus, etc. (Honorary Secretary, Dr. Samuel Macaulay, 49, Jesmond Road, Newcastle-onTyne.)

Section F.-Otology, comprising Models, Casts, Drawings, Anatomical and Pathological Specimens, new Aural Instruments, etc. (Honorary Secretary, Mr. Walter Ridley, F.R.C.S., 6, Ellison Place, Newcastle-on-Tyne.)

Sections $A, C$, and $D$ will be held in the College of Medicine, Northumberland Road; Section $E$ in the Cambridge Hall, Northumberland Road (opposite the College of Medicine); Sections $B$ and $F$ will be accommodated in the College of Science, Barras Bridge.

N.B.-Exceptionally central and well-lighted rooms have been reserved for the commercial part of the Museum (Sections A, D, and E).

For Section A (Foods and Drugs) the examination hall of the College of Medicine has been set apart. This fine room measures 90 by 35 feet, and is splendidly lighted by windows 14 feet high, while it opens directly out of the reception room.

The room reserved for Section D (Surgical Appliances,Books, and Microscopes) measures 70 feet by 30 feet, with roof and east lights, and in immediate proximity to the the Sections of Medicine, Surgery, Ophthalmology, and Anatomy and Physiology.

The Cambridge Hall, which has been secured for Section $\mathbf{E}$ (Sanitary and Ambulance Appliances) will afford about 4,000 square feet of floor space, and is situated immediately opposite to the College of Medicine.

Exhibitors (other than members of the medical profession) will be charged for the space occupied in the different Sections. Regulations and plans will be sent out to the trade exhibitors early in May.

Communications on general matters connected with the Museum, or respecting advertisements in the Museum Catalogue, should be addressed to Robert Howden, M.B., University of Durham College of Medicine, Newcastle-onTyne.

All intimations regarding exhibits must be sent in before June 29th, and a brief description of each exhibit, for insertion in the Museum Catalogue, must be in the hands of the respective secretaries by that date. ROBERT Howden, M.B.,

University of Durham College of Medicine, Newcastle-on-Tyne. W. G. RICHARDSON, F.R.C.S., The Dispensary, Newcastle-on-Tyne

Honorary Secretaries to the Museum Subcommittee. 